Supporting information for

\title{
Insight into the Working Mechanism of Quenchbody: Transition of the Dye around Antibody Variable Region That Fluoresces upon Antigen Binding
}

Hiroyuki Ohashi, ${ }^{\dagger, \downarrow}$ Takashi Matsumoto, ${ }^{\dagger}$ Hee-Jin Jeong, ${ }^{\dagger, \S}$ Jinhua Dong, ${ }^{\S}$ Ryoji Abe, ${ }^{\ddagger}$ and Hiroshi Ueda ${ }^{*} \dagger, \S$

${ }^{\dagger}$ Department of Chemistry and Biotechnology, School of Engineering, 7-3-1 Hongo, Bunkyo-ku, Tokyo 113-8656, Japan;

\$ Ushio Incorporated, 6409 Motoishikawa-cho, Aoba-ku, Yokohama 225-0004, Japan

${ }^{\S}$ Laboratory for Chemistry and Life Science, Tokyo Institute of Technology, 4259-R1-18, Nagatsuta-cho, Midori-ku, Yokoyama, Kanagawa 226-8503, Japan;

*Corresponding author: ueda@res.titech.ac.jp

$\begin{array}{ll}\text { EXPERIMENTAL PROCEDURES } & \text { S2 }\end{array}$

Figure S1. Fluorescence Polarization (FP) assay of anti-BPA Q-body. S5

$\begin{array}{ll}\text { REFERENCES } & \text { S6 }\end{array}$ 


\section{EXPERIMENTAL PROCEDURES}

\section{Materials}

pROX-FL92.1 amber harboring anti-BGP scFv gene and anti-BPA scFv gene were made as described ${ }^{1}$. PureYield plasmid miniprep kit was from Promega (Tokyo, Japan). RYTS cell-free translation kit and dye (TAMRA and ATTO520)-labeled tRNA were from ProteinExpress (Chiba, Japan). 5(6)-TAMRA C6 maleimide was from AAT Bioquest (Sunnyvale, CA). His Spin Trap column was from GE Healthcare KK (Tokyo, Japan). UltraFree-0.5 centrifugal device was from Millipore (Billerica, MA). The 7 aa C-terminal peptide for human osteocalcin (BGP-C7, $\mathrm{NH}_{2}-\mathrm{RRFYGPV-COOH,} \mathrm{MW:} \mathrm{894)} \mathrm{was} \mathrm{obtained} \mathrm{from} \mathrm{Genscript} \mathrm{(Piscataway,} \mathrm{NJ).}$ Bisphenol A (BPA) was from Wako Pure Chemicals (Osaka, Japan). Bovine serum albumin (BSA) was from Rockland (Philadelphia, PA). Deoxynivalenol (DON) was from Sigma-Aldrich (Atlanta, GA). A methamphetamine (MP) analog 3-[(2S)-2-(methylamino)propyl]phenol (MP-OH) was from NetChem Inc. (New Brunswick, NJ). All the water used was purified with Milli-Q (Millipore KK).

\section{Cell free translation and purification}

The synthesis of $\mathrm{scFv}$ position-specifically incorporated with fluorescence dye(s) was performed using an Escherichia coli (E. coli) cell-free translation system (RYTS kit) according to the manufacturer. Briefly, the reaction mixture $(50 \mu \mathrm{L})$ comprised of $16 \mu \mathrm{L}$ of $E$. coli lysate, $0.5 \mu \mathrm{L}$ of $150 \mu \mathrm{M}$ methionine, $2.5 \mu \mathrm{L}$ of enzyme mixture, $25 \mu \mathrm{L}$ of reaction mixture, $150 \mathrm{ng}$ of plasmid DNA, and 400 pmol of aminoacyl-tRNAs conjugated with either TAMRA or ATTO520, was prepared and incubated for $2 \mathrm{~h}$ at $25^{\circ} \mathrm{C}$.

The full-length synthesized protein with C-terminal His-tag was subsequently purified with a His Spin Trap Column. First, the column was primed by $400 \mu \mathrm{L}$ of wash buffer $(20 \mathrm{mM}$ phosphate, $0.5 \mathrm{M}$ sodium chloride $(\mathrm{NaCl}), 60 \mathrm{mM}$ imidazole, $0.1 \%$ polyoxyethylene(23)lauryl 
ether, $\mathrm{pH}$ 7.4). Then the reaction mixture, which was diluted in $350 \mu \mathrm{L}$ of wash buffer, was applied to the column. After incubation at $25^{\circ} \mathrm{C}$ for $15 \mathrm{~min}$, the column was washed three times with $500 \mu \mathrm{L}$ of wash buffer. Finally, the Q-body was eluted twice with $200 \mu \mathrm{L}$ of elution buffer (20 mM phosphate, $0.5 \mathrm{M} \mathrm{NaCl}, 0.5 \mathrm{M}$ imidazole, $0.1 \%$ polyoxyethylene(23)lauryl ether, $\mathrm{pH}$ 7.4). The eluent was subjected to an UltraFree- 0.5 centrifugal device and equilibrated with PBST $(0.05 \%$ Tween 20 in phosphate buffered saline, $10 \mathrm{mM}$ phosphate, $137 \mathrm{mM} \mathrm{NaCl}$, $2.7 \mathrm{mM}$ potassium chloride, $0.05 \%$ Tween20, $\mathrm{pH} 7.4$ ) to exchange buffers. The concentration

of buffer-exchanged Q-body was determined by comparing the fluorescence intensities of known concentrations of the dye and of the sample in $7 \mathrm{M}$ guanidine hydrochloride, $\mathrm{pH}$ 7.4. The resultant Q-body reagent was dispensed at $2 \mu \mathrm{g} / \mathrm{mL}$ and stored at $-80{ }^{\circ} \mathrm{C}$.

For the preparation of Fab-type Q-body (UQ-body), two plasmid DNAs encoding Fd and light chain, respectively, were added as templates, and the product was further purified using anti-Flag M2 Sepharose beads as described ${ }^{2,3}$. For the preparation of anti-MP UQ-body, the amber codon in the heavy chain ProX tag was modified to that encoding Cys (TGC), and the Fab protein purified with His Spin Trap column was labeled with TAMRA C6 maleimide, before purification with anti-Flag beads.

\section{Q-body ELISA}

Q-body solutions (50-100 pM) were added into a 96-well microplate pre-coated with 10 $\mu \mathrm{g} / \mathrm{mL}$ of anti-TAMRA antibody in PBS at $4^{\circ} \mathrm{C}$ for $16 \mathrm{~h}$, in the absence or presence of antigen (1 $\mu \mathrm{M}$ BGP-C7, $10 \mu \mathrm{M}$ BPA, $1 \mu \mathrm{M}$ DON, or $100 \mu \mathrm{M}$ MP-OH). The wells were washed with PBST and incubated with diluted Penta-His HRP conjugate monoclonal antibody (Qiagen KK, Tokyo, Japan) in PBST at $25^{\circ} \mathrm{C}$ for $1 \mathrm{~h}$. The microplate was then washed with PBST and developed with substrate solution containing 3,3',5,5' -tetramethylbenzidine (Sigma KK, 
Tokyo, Japan). The reaction was stopped with $2 \mathrm{~N} \mathrm{H}_{2} \mathrm{SO}_{4}$ and the absorbance read at $450 \mathrm{~nm}$ with a reference at $655 \mathrm{~nm}$ using a microplate reader Model 680 (Bio-Rad, Tokyo, Japan).

\section{Fluorescence Polarization}

Fluorescence polarization (FP) measurements for ATTO520-labeled Q-bodies were made on a GENios Pro (Tecan, Männedorf, Switzerland) using a 485-nm excitation filter and a 535-nm

emission filter, whereas those for TAMRA-labeled UQ-bodies were performed on a fluorescence spectrophotometer FP-8500 (JASCO, Tokyo, Japan) equipped with a pair of polarization filters, wherein the excitation and emission wavelengths were set at $530 \pm 10 \mathrm{~nm}$ and $580 \pm 10 \mathrm{~nm}$, respectively.

Fluorescence polarization, expressed in the unit of $1 / r$ was calculated by

$$
\frac{1}{r}=\left\{\frac{F_{||}-F_{\perp}}{F_{||}+2 F_{\perp}}\right\}^{-1}
$$

Where $F_{\|}$is the emission intensity parallel to the excitation plane and $F_{\perp}$ is the intensity perpendicular to the excitation plane. In this study, we used $1 / r$ that corresponds to the average degree of dye mobility in the Q-bodies. To measure the FP, 100 or $250 \mu \mathrm{L}$ of $0.5 \mathrm{nM}$ Q-body in PBST containing 1\% bovine serum albumin (Sigma) was prepared in a Corning 3694 96-well half-area black plate (Corning-Costar Japan, Tokyo, Japan) or a microcuvete, respectively, to which the antigen was added. After each addition, the solution was incubated for $3 \mathrm{~min}$ at $25^{\circ} \mathrm{C}$ prior to the FP measurements. 


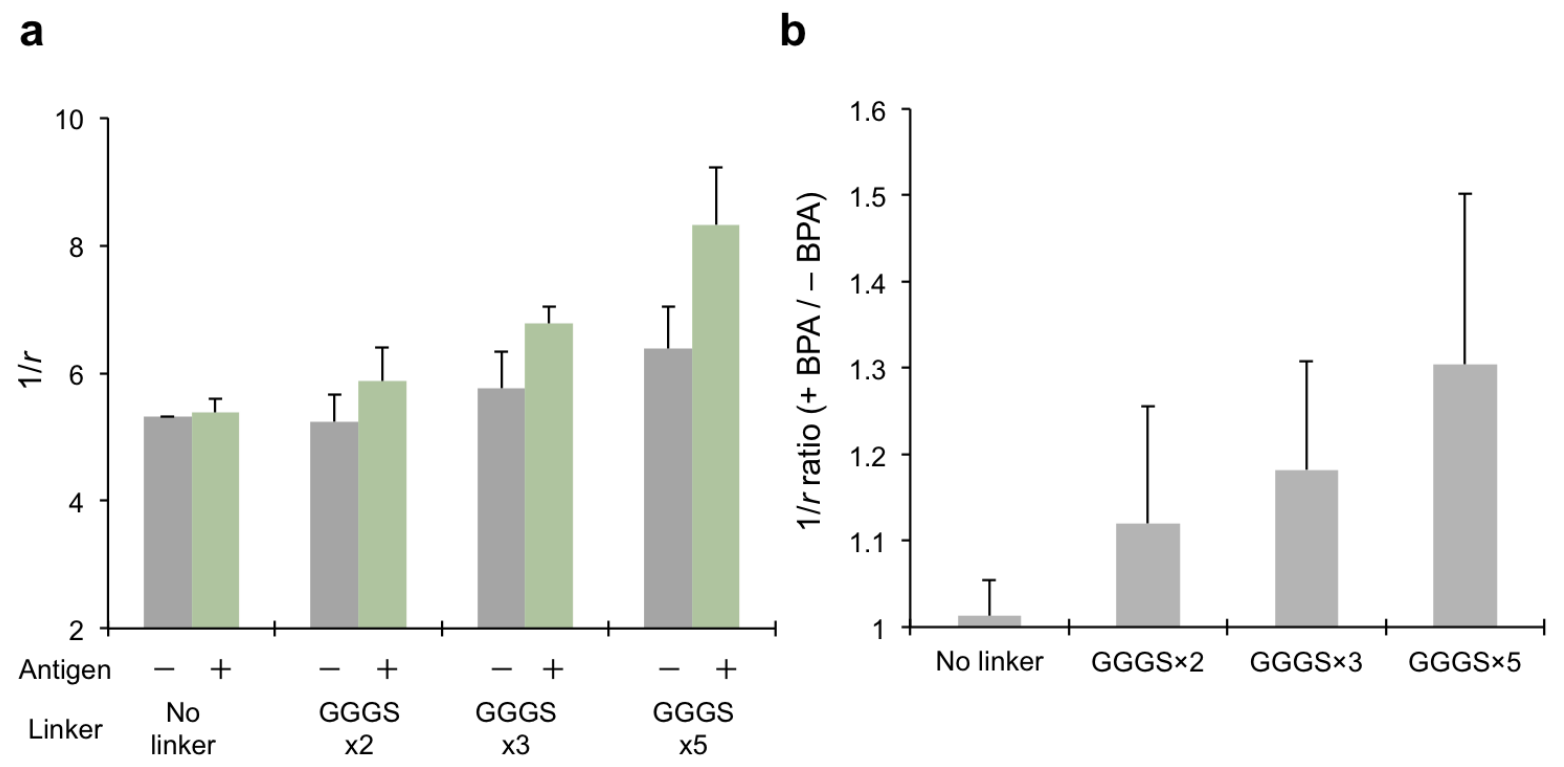

Figure S1. Fluorescence Polarization (FP) assay of anti-BPA Q-body. (a) Comparison of 1/r from FP measurements using anti-BPA Q-bodies with four different N-terminal tag lengths. (b) Ratios of $1 / r$. The average of three measurements with 1 SD is shown. 


\section{REFERENCES}

(1) Abe, R., Ohashi, H., Iijima, I., Ihara, M., Takagi, H., Hohsaka, T., and Ueda, H. (2011) "Quenchbodies": quench-based antibody probes that show antigen-dependent fluorescence. $J$. Am. Chem. Soc. 133, 17386-94.

(2) Abe, R., Jeong, H.-J., Arakawa, D., Dong, J., Ohashi, H., Kaigome, R., Saiki, F., Yamane, K., Takagi, H., and Ueda, H. (2014) Ultra Q-bodies : quench-based antibody probes that utilize dye-dye interactions with enhanced antigen-dependent fluorescence. Sci. Rep. 4, 4640.

(3) Yoshinari, T., Ohashi, H., Abe, R., Kaigome, R., Ohkawa, H., and Sugita-Konishi, Y. (2015) Development of a rapid method for the quantitative determination of deoxynivalenol using Quenchbody. Anal. Chim. Acta 888, 126-30. 